\title{
Swelling Kinetics and Corneal Hydration Level of Kaolin- in-HPMC Hydrogel Film
}

\author{
ARUNIMA PRAMANIK, R. N. SAHOO, A. NANDA, K. P. PATTNAIK1 AND S. MALLICK* \\ School of Pharmaceutical Sciences, Siksha O Anusandhan (Deemed to be University), Bhubaneswar-751003, India
}

Pramanika et al.: Swelling Kinetics and Corneal Hydration Level

\begin{abstract}
In this investigation, the effect of kaolin on hydration kinetics and swelling behavior of hydroxypropyl methylcellulose ocular film was studied. Gradual reduction in the extent of and rate of swelling of the film was noticed with increasing the content of kaolin. Peppas model revealed that the diffusion coefficient was increased in the presence of kaolin and also increased for the film of higher viscosity polymeric film. Peppas model suggested that the polymeric film followed the diffusion-controlled swelling mechanism. The Peleg rate constant was increased from 1.69 to $44.39 \mathrm{~h} / \mathrm{g}$ indicating the initial water adsorption rate in the decreasing order while Peleg capacity constant did not vary significantly in the presence and absence of kaolin indicating lack of remarkable change of water adsorption capacity. The presence of kaolin in the film could maintain a safe corneal hydration level.
\end{abstract}

Key words: Kaolin; corneal hydration level; swelling and erosion; Peleg's kinetic model

Swelling of polymer plays an important role in hydrogel-based transmucosal drug delivery systems. Swelling facilitates patterned drug release from matrix due to water penetration into matrix and polymer chain relaxation. Intimate contact between polymer and mucosal tissue brings about bioadhesion via swelling by entanglement of polymer and mucin chains of mucosal membrane lining ${ }^{[1]}$. The mucoadhesion with the mucus layer covered the mucosal epithelial surface depends on the interaction capability of the natural and synthetic polymers, which further effects the controlled release of drug substances ${ }^{[2]}$. Swelling is an important phase for ocular polymeric film as swelling of film assist to adhere to the corneal mucous layer and improve ocular residence time. Hydroxypropyl methylcellulose (HPMC) is widely used in mucosal drug delivery systems due to its biodegradability and biocompatibility. HPMC undergoes hydration followed by swelling when comes in contact with aqueous media. Films prepared by HPMC transform hydrogel like structure by cross-linking of polymer after swelling and allow aqueous biological fluid absorption. Hydrogel has been used for drug delivery ${ }^{[3,4]}$ and also in tissue engineering, biosensors and in biomedical field ${ }^{[5,6]}$. The swelling of hydrogel is an important parameter in influencing the controlled release of a drug. Clay minerals like kaolin are valuable industrial minerals

*Address for correspondence E-mail:profsmallick@gmail.com

March-April 2020 and of considerable importance in drug delivery. The major elemental features of kaolin such as, sorption capacity, rheological properties, swelling capacity, high specific surface area and chemical inertness could be explored in designing hydrogel based drug delivery devices. The quality and functionality of the hydrogel could further be investigated by controlling the swelling process with kaolin incorporation and not too many studies have been published this area. In the present study hydration and swelling pattern of dexamethasone (DXA) incorporated HPMC hydrogel in presence and absence of kaolin have been investigated. The swelling behavior of the HPMC matrix films was characterized using Peleg's kinetic model. Experimental data of swelling value was compared with the predictive value of swelling obtained from the model fitting.

\section{MATERIALS AND METHODS}

DXA was supplied by Sigma Company as a gift. Ethanol (absolute for analysis) was purchased from Merck

This is an open access article distributed under the terms of the Creative Commons Attribution-NonCommercial-ShareAlike 3.0 License, which allows others to remix, tweak, and build upon the work non-commercially, as long as the author is credited and the new creations are licensed under the identical terms

Accepted 03 February 2020

Revised 17 January 2020

Received 04 December 2019

Indian J Pharm Sci 2020;82(2):306-314 
(Germany). HPMC E5 and HPMC K15M, kaolin and triethanolamine were procured from Burgoyne Co. (India), Qualikems Fine Chem Ltd., (Vadodara) and Merck Pvt Ltd (Mumbai), respectively.

\section{Hydrogel film preparation:}

The DXA polymeric hydrogel film was prepared by solvent casting and solvent evaporation technique ${ }^{[7,8]}$. Polymeric dispersions of HPMC E5 and HPMC $\mathrm{K} 15 \mathrm{M}$ were prepared by continuous stirring of swollen polymer at room temperature for $24 \mathrm{~h}$. Kaolin powder was dispersed in distilled water by stirring for $24 \mathrm{~h}$ at room temperature and the upper layer was incorporated into aqueous gel of HPMC E5 and HPMC $\mathrm{K} 15 \mathrm{M}$ and stirring continued for $1 \mathrm{~h}$. DXA acetate and triethanolamine (as plasticizer) ${ }^{[4]}$ were dissolved in ethanol and incorporated into the polymer-kaolin dispersion by continuous stirring for $3 \mathrm{~h}$. The film was produced by casting the final dispersion followed by drying in an incubator at $60^{\circ}$ for $24 \mathrm{~h}$.

\section{Moisture content and moisture uptake:}

Small pieces of the film $(0.25 \mathrm{~g})$ were weighed $\left(\mathrm{W}_{1}\right)$ and placed in desiccators containing activated silica at room temperature for $24 \mathrm{~h}$ or more. The films were removed from desiccators and weighed $\left(\mathrm{W}_{2}\right)$ until it showed a constant weight. Moisture content was determined using the formula $\left(\mathrm{W}_{1}-\mathrm{W}_{2}\right) /\left(\mathrm{W}_{2}\right)$ for each film and expressed as a percent value. Dried films were taken out of the desiccators and placed in desiccators over the supersaturated solution of sodium nitrite, sodium chloride and potassium chloride, to maintain 65,75 , and $85 \%$ relative humidity, respectively. The films were weighed periodically at respective humidity condition until three measurement of constant weight for the films were obtained. Moisture uptake was evaluated as the difference between final and initial weight with respect to initial weight and expressed as a percent value.

\section{Fourier transform infrared (FTIR) spectroscopy:}

FTIR spectra of DXA and the formulated samples were run using the $\mathrm{KBr}$ pressed-disk method on a Jasco FT/IR-4100. The FTIR spectra were recorded in transmission mode by accumulating 80 scans at a resolution of $4 \mathrm{~cm}^{-1}$ in the range of $400-4000 \mathrm{~cm}^{-1}$.

\section{Scanning electron microscopy (SEM):}

The morphology of the crystalline DXA, kaolin and samples were investigated using scanning electron microscopy with a Jeol/EO\$CM_Version 1.0 Scanning Electron Microscope JSM-6390, operating at $5 \mathrm{kV}$. Prior to imaging, all samples were sputter-coated with a gold layer under argon atmosphere by a sputter apparatus. The film surfaces were viewed at different between 1000-10,000 magnification.

\section{Swelling and erosion studies:}

Swelling test was carried out at room temperature using following $\mathrm{Eqn}^{[9]}$. A piece $(2$ by $2 \mathrm{~cm}$ ) of all prepared dry film formulation has been weighed $\left(W_{o}\right)$ and placed in each separate petri dishes containing $25 \mathrm{ml}$ of phosphate buffer $\mathrm{pH}$ 7.4. Then the samples were removed at predetermined time intervals up to $6 \mathrm{~h}$ from buffer and dabbed with a filter paper to remove excess water. Films were reweighed $\left(W_{s}\right)$ and swelling content $(\mathrm{g} / \mathrm{g})^{[10,11]}$ was calculated using the Eqn., $\mathrm{S}=\mathrm{W}_{\mathrm{s}}-\mathrm{W}_{0} / \mathrm{W}_{0}$. Where $S$ is the swelling content $(\mathrm{g} / \mathrm{g})$ of film, $W_{s}$ is the final weight of swollen film at time $t$, and $\mathrm{W}_{\mathrm{o}}$ is the initial weight of the dry film.

For erosion studies these films from swelling studies were dried at $40^{\circ}$ in a hot air oven overnight. Films were cooled to room temperature and weighed again $\left(\mathrm{W}_{\mathrm{e}}\right)$ and erosion index was calculated from swelling studies, $\mathrm{E}=\mathrm{W}_{0}-\mathrm{W}_{\mathrm{e}} / \mathrm{W}_{0}$. Swelling rate demonstrated the change in swelling content per unit time of film and calculated using the Eqn., $S_{r}=S_{t+\Delta t}-S_{t} / \Delta$, where $S_{r}$ is the swelling rate of the film, $S_{\mathrm{t}}$ is the swelling content of the film at any time $t$, and $S_{t+\Delta t}$ is the swelling content at $t+\Delta t$ based on dry content. Swelling of polymer involves diffusion of water, the swelling kinetics and diffusion of polymer structure have been explained by Peppas law, Higuchi model $^{[12]}$ for understanding of the mechanism of solvent diffusion. $\mathrm{F}=\mathrm{S}_{\mathrm{t}} / \mathrm{S}_{\max }=\mathrm{Kt}^{\mathrm{n}} \mathrm{Q}=\mathrm{K}^{\mathrm{H}} \times \mathrm{V}_{\mathrm{t}}$, where, $\mathrm{F}$ is the fraction of swelling content, $\mathrm{S}_{\max }$ is the maximum swelling content of the film, $S_{t}$ is the swelling content of the film at any time $\mathrm{t}, \mathrm{K}$ is constant depends upon the changing of gel network structure and $\mathrm{n}$ is the diffusion exponential of solvent. The type of diffusion can be decided from the $n$ value. Swelling kinetics examined by another important parameter as coefficient of diffusion. Coefficient of diffusion (D) of square shape film can be calculated from the Eqn. arranged form of Fick's II law, which is, $D=a^{2}(k / 4)^{1 / n}$. Where $D$ is the coefficient of diffusion expressed as $\mathrm{cm} 2 / \mathrm{s}$, and a is the side of square film in $\mathrm{cm}$. Mathematical modeling for swelling kinetics has been described by two-parameter based Peleg's model ${ }^{[13]}$ as, $\mathrm{S}_{\mathrm{t}}=\mathrm{S}_{\mathrm{o}} \pm \mathrm{t} / \mathrm{K}_{1}+\mathrm{K}_{2} \mathrm{t}$, where $\mathrm{S}_{\mathrm{o}}$ is the swelling content at time $0(\mathrm{~g} / \mathrm{g}), \mathrm{S}_{\mathrm{t}}$ is the swelling content $(\mathrm{g} / \mathrm{g})$ at time $\mathrm{t}, \mathrm{k}_{1}$ is the Peleg rate constant $(\mathrm{h} / \mathrm{g})$ and $\mathrm{k}_{2}$ is the Peleg capacity constant of the model (g). In 
the Eqn. \pm indicates the process followed by absorption and/or adsorption $(+)$, or the process followed by drying and/or desorption (-). The positive swelling process followed by polymer matrix induced by water uptake can be expressed by rewriting the above equation in linearized form. The linearized form of Peleg Eqn. plotted as the regress of swelling content $v s$. time using the Eqn., $\mathrm{t} /\left(\mathrm{s}_{\mathrm{t}}-\mathrm{S}_{0}\right)=\mathrm{K}_{1}+\mathrm{K}_{2} \mathrm{t}$.

\section{Measurement of corneal hydration level:}

The whole eye ball of goat was collected from local butcher's market and rinsed in saline water within $1 \mathrm{~h}$ after sacrificing the goat. Each test cornea was carefully removed from the scleral ring and weighed $\left(\mathrm{W}_{\mathrm{w}}\right)$. Corneal hydration level (HL) of the film formulations was investigated gravimetrically by measuring total water content by desiccation at $100^{\circ}$ for $6 \mathrm{~h}$ to determine dry corneal weight $\left(\mathrm{W}_{\mathrm{d}}\right)$. The corneal hydration level $(\mathrm{HL} \%)$, defined as $\left(1-\left(\mathrm{W}_{\mathrm{w}} / \mathrm{W}_{\mathrm{d}}\right)\right) \times 100$ was determined both on untreated and treated corneas using film formulation.

\section{Statistical analysis:}

The statistical fitting of a model to the experimental data was analyzed using Origin Pro 8.0 (OriginLab, Northampton, MA) software ${ }^{[14]}$ using the nonlinear regression analysis. The 3 values of $R^{2}, \chi^{2}$, and root mean square error (RMSE) were utilized to evaluate the fitness of the model to the experimental data. RMSE = $\left(1 / \mathrm{N} \Sigma_{\mathrm{i}}^{\mathrm{N}}=1\left(\mathrm{SR}_{\mathrm{pre}, \mathrm{i}}-\mathrm{SR}_{\text {exp, } \mathrm{i}}\right)^{2}\right)^{1 / 2}$.

\section{RESULTS AND DISCUSSION}

Table 1 shows moisture content at $25^{\circ}$ and moisture uptake at 65,75 , and $85 \%$ relative humidity of DXA film composed of HPMC and kaolin. A progressive diminution of both moisture content and moisture uptake was observed with increasing kaolin content in the formulations. Moisture uptake has also been enhanced gradually when $\mathrm{RH}$ was increased from 65 to $85 \%$ in all the respective formulations ${ }^{[8]}$. It was observed that the \% moisture uptake of the films with highest kaolin content of HPMC E5 and HPMC K15M matrices decreased from $5.34 \pm 0.011$ to $3.50 \pm 0.019$ and $6.52 \pm 0.032$ to $4.54 \pm 0.049$, respectively at $65 \% \mathrm{RH}$ when compared to those without kaolin. Kaolin content $(1: 1)$ in the film significantly decreased \% moisture content in comparison to its absence from $2.27 \pm 0.006$ to $1.16 \pm 0.011$, and $3.29 \pm 0.006$ to $2.19 \pm 0.011$ in HPMC E5 and HPMC K15M films, respectively. These results suggested that the presence of kaolin improved the water resistance of HPMC matrix formulation. As kaolin possessed certain level of hydrophilicity ${ }^{[15]}$ and capability of hydrogen bond formation, the interaction site availability for water retention was less due to the affinity between kaolin and DXA and between kaolin and HPMC. It has also been observed that the moisture content and uptake varied for different HPMC grades.

Infrared spectroscopy is the most appropriate universal technique for analyzing pharmaceutical solids. The appearance of new and disappearance of existing absorption bands, broadening of bands, and alteration in intensity are the main evidences to the nature of drug-excipient interaction ${ }^{[16,17]}$. Infrared spectroscopy provides valuable information about the peak positions, intensities, widths and shapes, in a spectrum. Fig. 1 shows IR spectra of DXA, kaolin, and film containing different amount of kaolin. The IR spectrum of DXA showed the characteristic absorption bands of important functional groups such as 3000-2800 for $\mathrm{CH}_{2}$ group, 885 for axial deformation of C-F group, 1718 for carbonyl of aliphatic ester, 1665 for $\mathrm{C}=\mathrm{O}$ group, 1621 $\mathrm{C} \equiv \mathrm{C}^{[18]}$. The broadening of absorption band such as 3000-2800 was observed in spectra of all formulations due to polymer. The characteristic absorption band of

TABLE 1: MOISTURE CONTENT AND MOISTURE UPTAKE OF THE FILM FORMULATION

\begin{tabular}{|c|c|c|c|c|c|c|}
\hline \multirow[t]{2}{*}{ Film } & \multirow[t]{2}{*}{ Polymer } & \multirow[t]{2}{*}{ DXA: kaolin } & \multicolumn{3}{|c|}{$\begin{array}{l}\text { \% Moisture uptake at RH } \\
(\text { mean } \pm S D, n=3)\end{array}$} & \multirow{2}{*}{$\begin{array}{c}\% \text { Moisture } \\
\text { content } \\
(\text { mean } \pm S D, n=3)\end{array}$} \\
\hline & & & 65 & 75 & 85 & \\
\hline $\mathrm{DM}_{5} \mathrm{C}_{0}$ & HPMC E5 & No kaolin & $5.34 \pm 0.011$ & $12.21 \pm 0.019$ & $17.55 \pm 0.020$ & $2.40 \pm 0.006$ \\
\hline $\mathrm{DM}_{5} \mathrm{C}_{1}$ & HPMC E5 & $1: 0.25$ & $4.65 \pm 0.013$ & $10.46 \pm 0.021$ & $16.27 \pm 0.019$ & $2.38 \pm 0.009$ \\
\hline $\mathrm{DM}_{5} \mathrm{C}_{2}$ & HPMC E5 & $1: 0.5$ & $4.20 \pm 0.020$ & $10.92 \pm 0.029$ & $16.80 \pm 0.031$ & $2.27 \pm 0.005$ \\
\hline $\mathrm{DM}_{5} \mathrm{C}_{3}$ & HPMC E5 & $1: 0.75$ & $4.16 \pm 0.025$ & $10.11 \pm 0.027$ & $15.47 \pm 0.023$ & $1.19 \pm 0.007$ \\
\hline $\mathrm{DM}_{5} \mathrm{C}_{4}$ & HPMC E5 & $1: 1$ & $3.50 \pm 0.019$ & $9.94 \pm 0.033$ & $14.61 \pm 0.030$ & $1.16 \pm 0.011$ \\
\hline $\mathrm{DM}_{15} \mathrm{C}_{0}$ & HPMC K15M & No kaolin & $6.52 \pm 0.032$ & $13.04 \pm 0.029$ & $23.91 \pm 0.031$ & $3.29 \pm 0.006$ \\
\hline $\mathrm{DM}_{15} \mathrm{C}_{1}$ & HPMC K15M & $1: 0.25$ & $5.59 \pm 0.039$ & $12.42 \pm 0.049$ & $21.73 \pm 0.052$ & $3.14 \pm 0.009$ \\
\hline $\mathrm{DM}_{15} \mathrm{C}_{2}$ & HPMC K15M & $1: 0.5$ & $4.90 \pm 0.041$ & $11.76 \pm 0.053$ & $19.60 \pm 0.037$ & $2.94 \pm 0.003$ \\
\hline $\mathrm{DM}_{15} \mathrm{C}_{3}$ & HPMC K15M & $1: 0.75$ & $4.80 \pm 0.047$ & $11.53 \pm 0.038$ & $19.23 \pm 0.082$ & $2.83 \pm 0.014$ \\
\hline $\mathrm{DM}_{15} \mathrm{C}_{4}$ & HPMC K15M & $1: 1$ & $4.54 \pm 0.049$ & $11.36 \pm 0.091$ & $18.18 \pm 0.079$ & $2.19 \pm 0.011$ \\
\hline
\end{tabular}




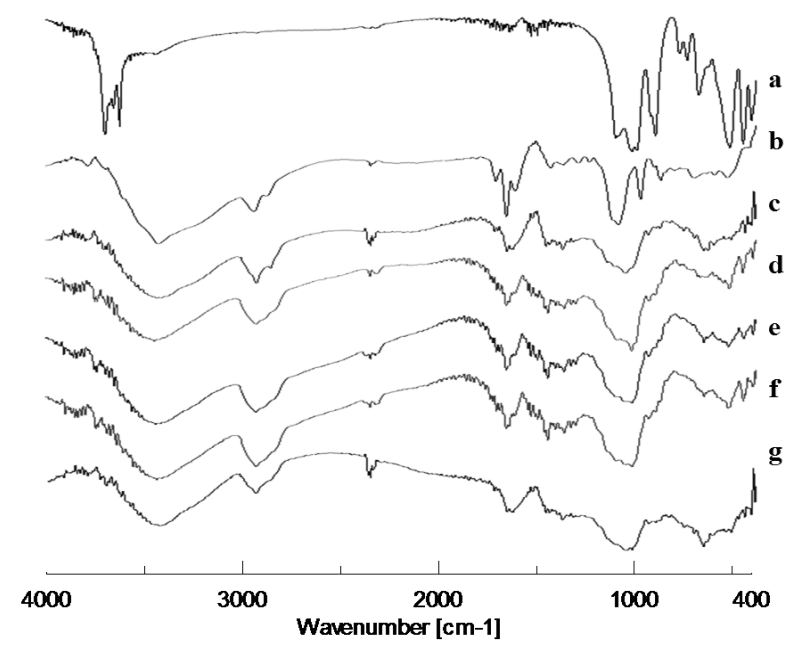

Fig. 1: FTIR spectra of kaolin, crystalline DXA and film formulations

FTIR spectra of a) kaolin, b) crystalline dexamethasone (DXA), and film formulations e) $\mathrm{DM}_{15} \mathrm{C}_{0}$, d) $\mathrm{DM}_{15} \mathrm{C}_{1}$, e) $\mathrm{DM}_{15} \mathrm{C}_{2}$ and f) $\mathrm{DM}_{15} \mathrm{C}_{4}$
DXA at 1665 could be observed clearly in IR spectra of all formulations. These result indicated that DXA was incorporated successfully in to the films. The main chemical property of DXA remained unchanged during the entire process. The spectrum of pure kaolin showed an intense absorption band at 1032 due to Si-O stretching in clay ${ }^{[19]}$. This absorption band shifted to higher wavelength in spectra of all formulations.

The IR spectra of DXA, kaolin and formulation demonstrated evidence for the interaction between kaolin and DXA. The absorption band shifting might occur due to hydrogen bonding of DXA with kaolin. Kaolin contains hydroxyl groups, outer hydroxyl group $(\mathrm{OuOH})$ positioned in the upper unshared plane and inner hydroxyl group ( $\mathrm{InOH})$ to be found in the lower unshared plane of the octahedral sheet. The observed absorption bands at $3693,3669,3649 \mathrm{~cm}^{-1}$ associated with the stretching of $\mathrm{OuOH}$ and at 3619 associated

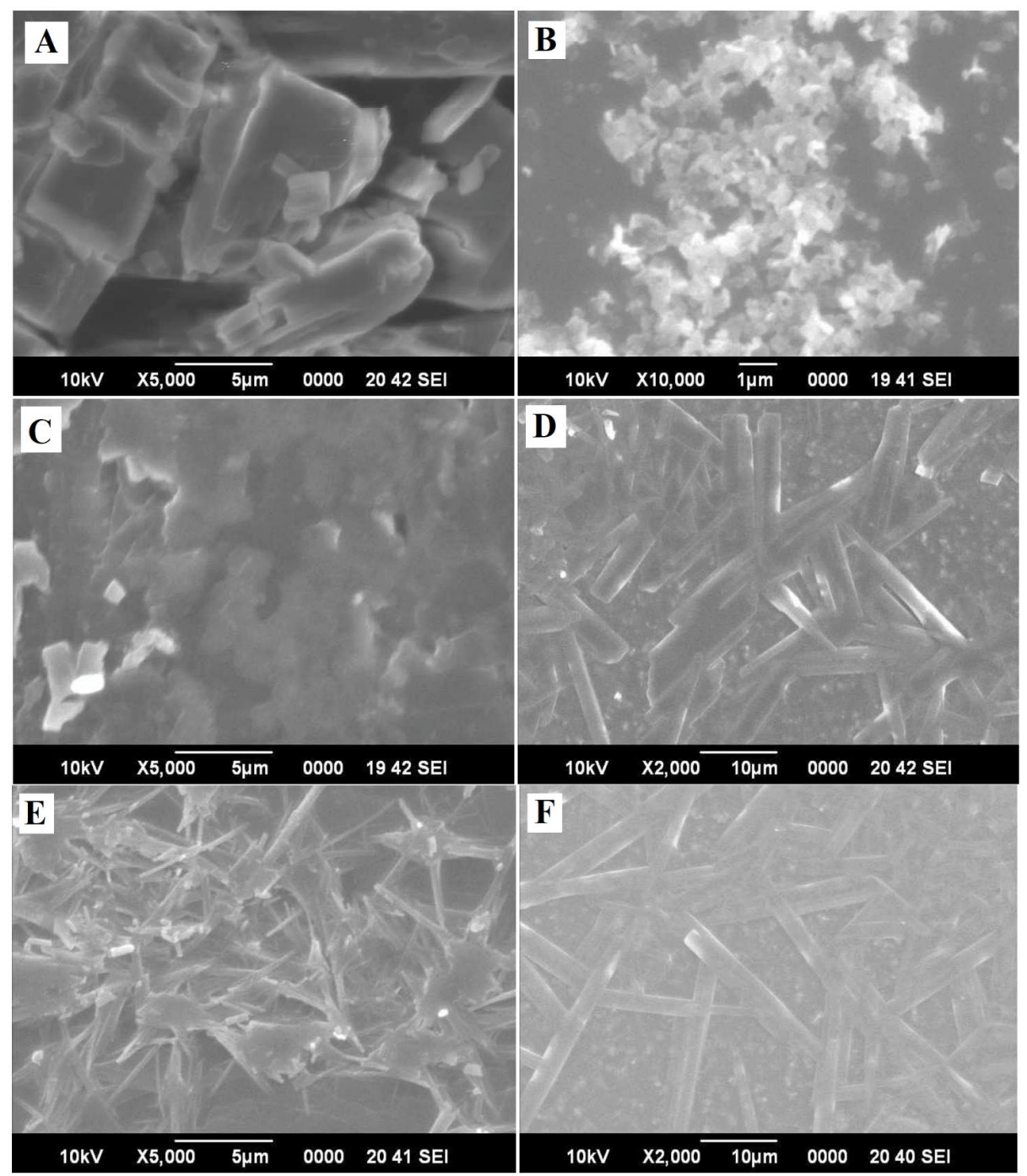

Fig. 2: SEM pictomicrographs of crystalline DXA, kaolin and formulations

SEM images of A) crystalline dexamethasone (DXA), B) kaolin and formulations C) $\left.\mathrm{DM}_{5} \mathrm{C}_{0}, \mathrm{D}\right) \mathrm{DM}_{5} \mathrm{C}_{4,} \mathrm{E}$ ) $\mathrm{DM}_{15} \mathrm{C}_{0}$ and F) $\mathrm{DM}_{15} \mathrm{C}_{4}$ 
with the stretching of $\mathrm{InOH}$ in $\mathrm{Al}-\mathrm{OH}^{[19]}$. Whereas the deformation band of $\mathrm{OH}$ linked to $2 \mathrm{Al}^{3-}$ observed at $913 \mathrm{~cm}^{-1[20]}$. The characteristic absorption band of kaolin at 1032 was broadened in the spectra of all formulations and this broadening was more with increasing content of kaolin in films. This result suggested the relatively stronger binding to DXA with increasing kaolin content.

Fig. 2 showed the scanning electron micrograph of pure DXA and kaolin, films in presence and absence of kaolin of both HPMC E5 and HPMC K15M matrices. The nano-sized kaolin particle was distinctly distributed into the film as confirmed by the SEM images (figs. 2D and 2F). The DXA crystals were observed in geometric plate shape. The plate shape of DXA has been converted to thin submicron and nanomicron fiber tubular shape of DXA. The tubular shape of DXA appeared comparatively thinner in presence of kaolin than absence of kaolin in film. The pseudohexagonalshape of kaolinite crystal was observed in fig. 2B, as it is reported in literature ${ }^{[21]}$. The intercalation kaolin particle with DXA might be the reason of the conversion of kaolin particle to tubular form. The result of intercalation of potassium acetate with kaolinite was revealed the nanotubular behavior of kaolinite ${ }^{[22]}$.

Swelling of polymer plays an important role in hydrogel-based transmucosal drug delivery systems. In this study swelling content of film measured to analyze the swelling capacity of polymer and kaolin in phosphate buffer saline ( $\mathrm{pH}$ 7.4), which have been related to the permeation of DXA from the film matrix. Swelling involves the process of water uptake followed by erosion or degradation of the polymer matrix of film. Hence, swelling proceeded faster than erosion which resulted in still remaining of incorporated DXA molecules in the film matrix. Fig. 3 shows the swelling content vs. time graph with varied kaolin content of HPMC E5 and HPMC K15M matrices. It has been observed that the maximum swelling occurred after $60 \mathrm{~min}$ and $6 \mathrm{~h}$ from the film matrix of HPMC E5 and HPMC K15M respectively. Swelling content of the film gradually decreased with increased content of kaolin in film. Presence of kaolin in the film sustained the swelling more when compared with its absence. This result indicated that the kaolin has the ability to improve the water resistance of the film matrix. Swelling was driven by water uptake, which depends upon the hydrophilicity and also morphology as macro voids, free volume, and crystal size. Kaolin caused the production of tortuous pathway and also formation of
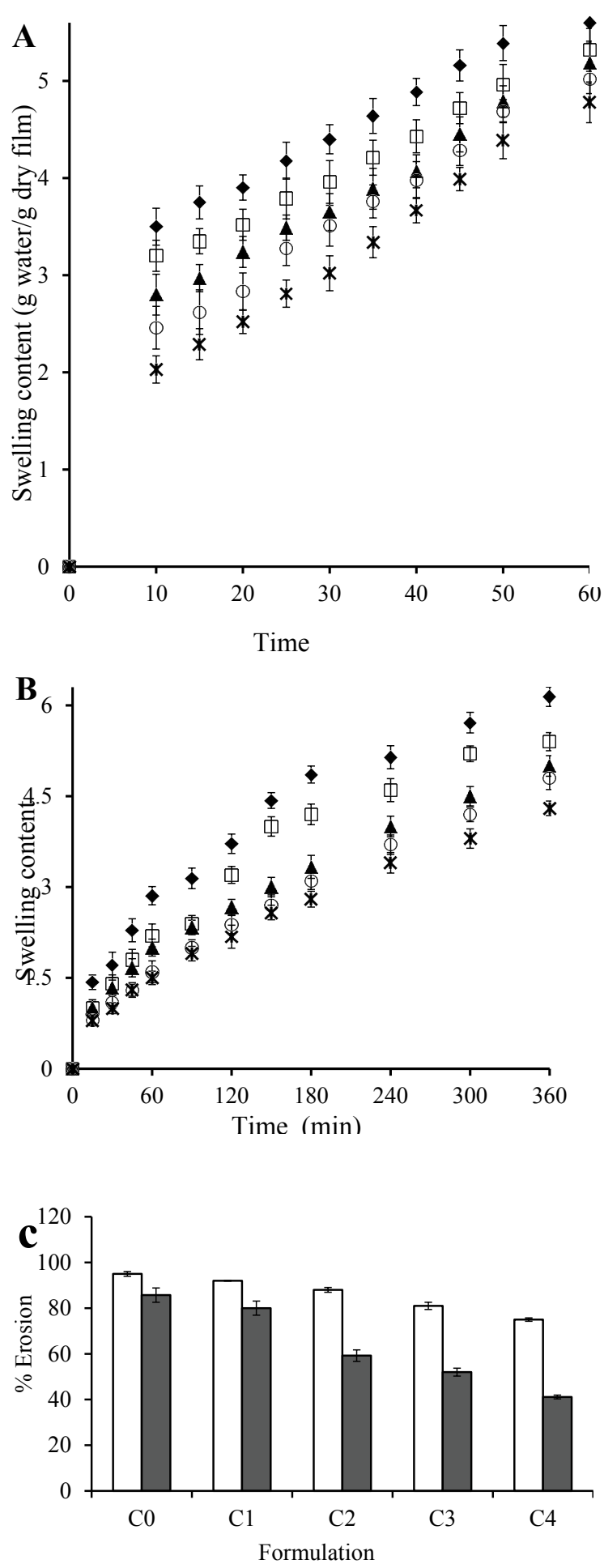

Fig. 3: Swelling of HPMC matrices and erosion of films as a function of kaolin content

Swelling (A) HPMC E5 matrices (•) DM5C0, (a) DM5C1, (A) DM5C2, (O) DM5C3 (×) DM5C4, (B)

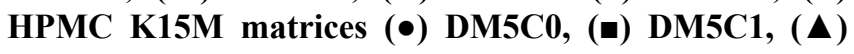
DM5C2, (O) DM5C3, (×) DM5C4, (C) Erosion of the films (ð) HPMCE5, (ロ) HPMCK15M as a function of kaolin content

denser cross-linking network ${ }^{[23]}$, which led to decrease the length of free way for water uptake due to its certain 
level of hydrophilicity ${ }^{[24]}$. Film of HPMC K15M matrix showed increased swelling content compared to the films of HPMC E5 matrix. This observation has been related to the polymer viscosity and molecular weight. Nominal viscosities of HPMC E5 and HPMC K15M are 5 and $15000 \mathrm{mPa} s$ respectively. High viscosity polymer matrix of HPMC K15M did not permit easy water uptake as a result of more compactly packed higher molecular weight molecules of polymer.

Erosion of polymeric matrix is commonly slower than the swelling or hydration process. Erosion causes diffusion of the loaded drug through the micropores of the polymer matrix induced by water uptake ${ }^{[1]}$. The extent of erosion at the end of $6 \mathrm{~h}$ of swelling in phosphate buffer ( $\mathrm{pH}$ 7.4) decreased progressively with increasing kaolin content in the films (fig. 3). Erosion of polymer becomes difficult in presence of kaolin because of entrapment of kaolin particle in the network of the HPMC-matrices. Kaolin-polymer affinity becomes relatively stronger with the increased kaolin content and resists the erosion and degradation of polymer of the film more and more.

The changes in the swelling rate as a function of swelling content of HPMC E5 and HPMC K15M films were shown in fig. 4 . These plots demonstrated that both the swelling content and swelling rate were decreased with increasing kaolin content of the films. Maximum swelling content in absence of kaolin was shown by $\mathrm{DH}_{5} \mathrm{C}_{0}$ and $\mathrm{DH}_{15} \mathrm{C}_{0}$, which were 5.6 and $6.14 \mathrm{~g}$ water/g dry film with corresponding swelling rates of 0.021 and $0.0071 \mathrm{~g}$ water/g dry film/min, respectively. Whereas the presence of maximum kaolin content in $\mathrm{DH}_{5} \mathrm{C}_{4}$ and $\mathrm{DH}_{15} \mathrm{C}_{4}$, caused decrease in the swelling content to the maximum extent, 4.78 and $4.6 \mathrm{~g}$ water/g dry film, with a consequent decrease in the swelling rate of 0.039 and $0.0083 \mathrm{~g}$ water $/ \mathrm{g}$ dry film $/ \mathrm{min}$, respectively.

Peppas Eqn. was used to investigate the mechanism of water diffusion into the hydrogel film. Table 2 represents the value of Peppas parameter ( $n, k$ and coefficient of determination) calculated from the slopes and intercepts of the plot of lnFvsln $t$ of all films. The type of diffusion was determined by the $n$ value defined as the Fick's diffusion transport. The swelling exponent $(n)$ value of this study showed $0.277-0.446$ and $0.485-0.58$ of films of HPMC E5 and HPMC K15M matrix, respectively. Hence, it could be concluded that the films of HPMC E5 matrix followed Fickian diffusion mechanism whereas films of HPMC K15M matrix followed anomalous diffusion. Diffusion coefficient $(D)$, one of the major parameter also used for the characterization
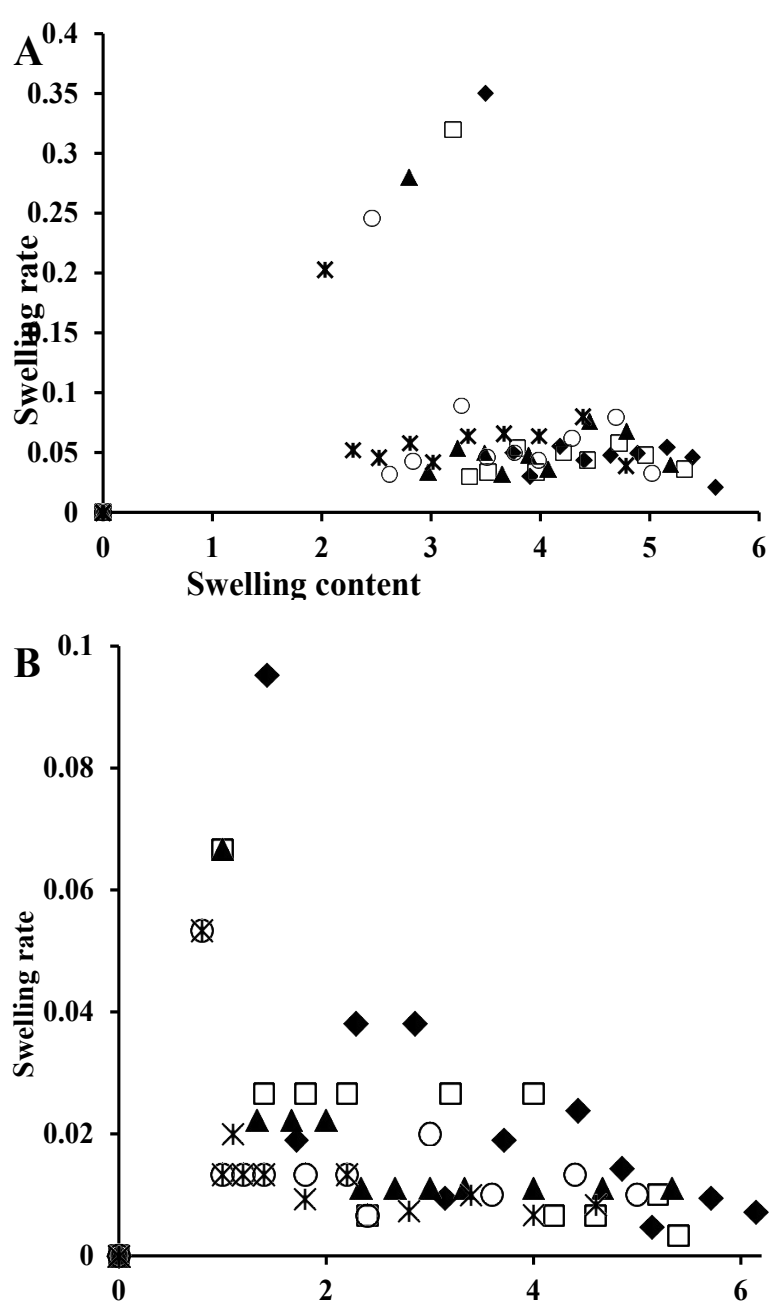

Fig. 4: Swelling rate vs swelling content of films of HPMC matrices with different kaolin content

Swelling rate vs swelling content of films of A) HPMC E5 matrix and B) HPMC K15M matrix with different

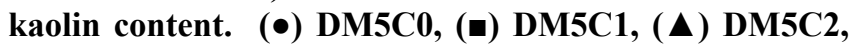
(O) DM5C3, (×) DM5C4 Swelling content was expressed as g water/g dry film and swelling rate as $A$ ) $g$ water/g dry film $/ \mathrm{h}$ and $B$. as g water $/ g$ dry film $/ \mathrm{min}$

of swelling of film. Swelling experiments suggested that $D$ value increased with increasing kaolin content in the film for both categories of HPMC matrix (Table 2). The diffusion coefficient varied from $4.51 \times 10^{-6}$ to 7.86 $\times 10^{-5}$, and $1.94 \times 10^{-4}$ to $3.06 \times 10^{-4} \mathrm{~m}^{2} / \mathrm{s}$ for HPMC E5 and HPMC K15M matrix, respectively. Higuchi model was utilized for determination of swelling kinetics and the parameters depicted in Table 2.

The swelling kinetics of films in presence and absence of kaolin were described by Peleg model and the constants $k_{1}, k_{2}, R^{2}, R M S E$ and $\chi^{2}$ were listed in Table 3. Mass transfer rate and maximum solvent absorption capacity explained by the assessment of the constant $k_{1}$ and Peleg capacity constant $\left(k_{2}\right)$, respectively. $k_{1}$ increased from 2.07 to 5.86 and 23.28 to 44.39 with 
TABLE 2: EFFECT OF KAOLIN ON HYDRATION AND KINETICS OF SWELLING OF THE FILM AS PER PEPPAS AND HIGUCHI MODEL

\begin{tabular}{lcccc} 
Film & $n$ & $\begin{array}{c}K_{p} \\
\left(\mathbf{R}^{2}\right)\end{array}$ & $\begin{array}{c}\boldsymbol{D} \\
\left(\mathrm{cm}^{2} / \mathrm{s}\right)\end{array}$ & $\begin{array}{c}K_{H} \\
\left(\boldsymbol{R}^{2}\right)\end{array}$ \\
\hline $\mathrm{DM}_{5} \mathrm{C}_{0}$ & 0.277 & $1.155(0.967)$ & $3.75 \times 10^{-6}$ & $0.487(0.985)$ \\
$\mathrm{DM}_{5} \mathrm{C}_{1}$ & 0.294 & $1.253(0.947)$ & $5.21 \times 10^{-6}$ & $0.524(0.986)$ \\
$\mathrm{DM}_{5} \mathrm{C}_{2}$ & 0.348 & $1.490(0.951)$ & $1.68 \times 10^{-5}$ & $0.526(0.966)$ \\
$\mathrm{DM}_{5} \mathrm{C}_{3}$ & 0.422 & $1.770(0.966)$ & $5.11 \times 10^{-5}$ & $0.588(0.978)$ \\
$\mathrm{DM}_{5} \mathrm{C}_{4}$ & 0.446 & $1.936(0.971)$ & $9.44 \times 10^{-5}$ & $0.618(0.972)$ \\
$\mathrm{DM}_{15} \mathrm{C}_{0}$ & 0.485 & $2.819(0.987)$ & $1.94 \times 10^{-4}$ & $0.324(0.987)$ \\
$\mathrm{DM}_{15} \mathrm{C}_{1}$ & 0.558 & $3.212(0.988)$ & $2.70 \times 10^{-4}$ & $0.311(0.982)$ \\
$\mathrm{DM}_{15} \mathrm{C}_{2}$ & 0.559 & $3.301(0.996)$ & $2.31 \times 10^{-4}$ & $0.268(0.996)$ \\
$\mathrm{DM}_{15} \mathrm{C}_{3}$ & 0.566 & $3.396(0.994)$ & $3.06 \times 10^{-4}$ & $0.266(0.993)$ \\
$\mathrm{DM}_{15} \mathrm{C}_{4}$ & 0.58 & $3.426(0.999)$ & $2.75 \times 10^{-4}$ & $0.235(0.995)$ \\
\hline
\end{tabular}

TABLE 3: EFFECT OF KAOLIN ON KINETICS OF SWELLING OF THE FILM AS PER PELEG MODEL

\begin{tabular}{lcccccc}
\hline Film & $\boldsymbol{S}_{0}$ & $\boldsymbol{k}_{1}$ & $\boldsymbol{k}_{2}$ & $\boldsymbol{R}^{2}$ & $R M S E$ & $\boldsymbol{x}^{2}$ \\
\hline $\mathrm{DM}_{5} \mathrm{C}_{0}$ & 0.0563 & 1.692 & 0.161 & 0.9781 & 0.2152 & 0.0640 \\
$\mathrm{DM}_{5} \mathrm{C}_{1}$ & 0.0754 & 2.070 & 0.171 & 0.9680 & 0.2416 & 0.0806 \\
$\mathrm{DM}_{5} \mathrm{C}_{2}$ & 0.1131 & 2.893 & 0.166 & 0.9632 & 0.2517 & 0.0874 \\
$\mathrm{DM}_{5} \mathrm{C}_{3}$ & 0.1430 & 3.979 & 0.150 & 0.9735 & 0.2126 & 0.0625 \\
$\mathrm{DM}_{5} \mathrm{C}_{4}$ & 0.1971 & 5.863 & 0.131 & 0.9730 & 0.2061 & 0.0586 \\
$\mathrm{DM}_{15} \mathrm{C}_{0}$ & 0.3009 & 17.762 & 0.126 & 0.9888 & 0.1896 & 0.0487 \\
$\mathrm{DM}_{15} \mathrm{C}_{1}$ & 0.1905 & 23.280 & 0.125 & 0.9895 & 0.1703 & 0.0392 \\
$\mathrm{DM}_{15} \mathrm{C}_{2}$ & 0.3886 & 34.525 & 0.129 & 0.9841 & 0.1785 & 0.0428 \\
$\mathrm{DM}_{15} \mathrm{C}_{3}$ & 0.3079 & 43.835 & 0.107 & 0.9914 & 0.1281 & 0.0221 \\
$\mathrm{DM}_{15} \mathrm{C}_{4}$ & 0.2891 & 44.391 & 0.133 & 0.9899 & 0.1241 & 0.0207 \\
\hline
\end{tabular}

the gradual increase in kaolin content compared to its absence $\left(\mathrm{DH}_{5} \mathrm{C}_{0}, 1.6919\right.$ and $\left.\mathrm{DH}_{15} \mathrm{C}_{0}, 17.7602\right)$ for HPMC E5 and HPMC K15M matrix, respectively. Whereas, reduction of $k_{2}$ observed from 0.181 to 0.131 and 0.134 to 0.108 for HPMC E5 and HPMC K15M matrix, respectively. It has been established that lower $k_{1}$ and $k_{2}$ value represented the higher initial solvent absorption rate and higher solvent absorption capacity, respectively ${ }^{[25]}$. The water absorption capacity of film increased in presence of increasing kaolin content may be due to the hydrophilicity level of kaolin. Kaolin resulted higher water absorption capacity of films, confirmed by the lower $k_{2}$ value. The $k_{1}$ raised as the kaolin content increased suggesting the decreased initial water absorption rate correspondingly. Also the water absorption capacity of HPMC K15M matrix observed higher than HPMC E5 matrix, confirmed by the reduced $k_{2}$ value of HPMC K15M matrix film rather than corresponding HPMC E5 film. The experimental and predicted values of swelling content based on Peleg model is depicted in fig. 5. $R^{2}(0.9632$ to 0.9914$), R M S E$ $(0.1241$ to 0.2517$)$ values revealed a good agreement of the predicted value with the experimental data of swelling content. The fitting of linearized form of Peleg model (Eqn, 8) demonstrated in fig. 6 as regress of swelling vs time. The results showed that the obtained parameter values were moderately matched to the Peleg model value and the calculated RMSE value appeared higher than the curve form of Peleg model (nonlinear curve fit in original software). $k_{1}$ was increased markedly from 1.692 to $44.391 \mathrm{~h} / \mathrm{g}$ in presence of gradual increase of kaolin in the films indicating the initial water absorption rate in the decreasing order. And swelling capacity of HPMC $\left(k_{2}\right)$ only varied slightly in the range of 0.107 to $0.171 \mathrm{~g}$ in presence and absence of kaolin indicating without remarkable change of water adsorption capacity fig. 7 .

Assessment of corneal hydration is used frequently for measuring damage to the corneal tissue. Normal
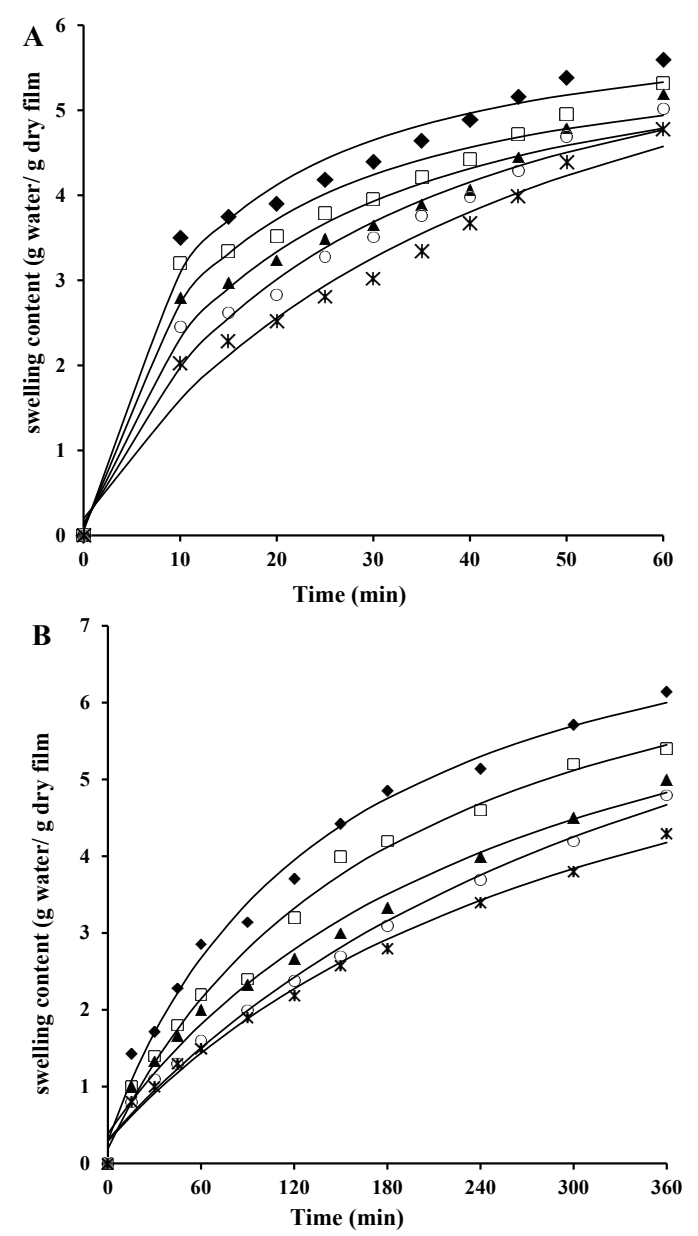

Fig. 5: Experimental and predicted swelling content values for films of HPMC matrices

Experimental and predicted values of swelling content based on Peleg model shown as curves of films prepared with A) HPMC E5 matrix and B) HPMC K15M matrix.

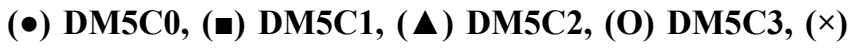
DM5C4 

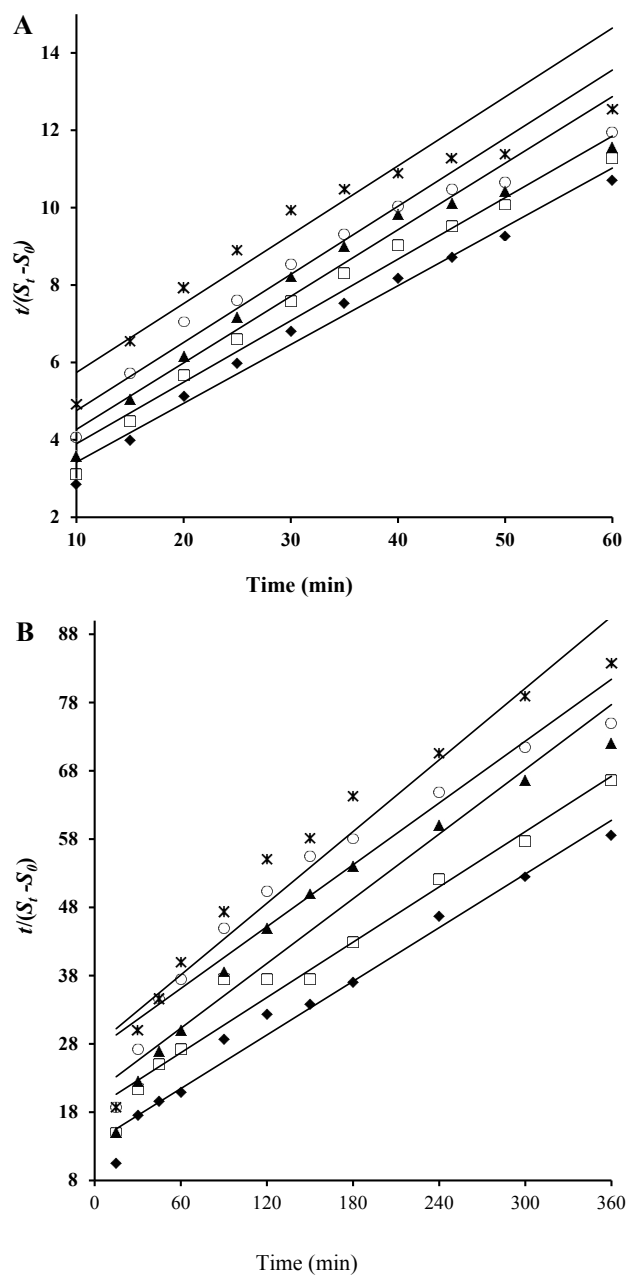

Fig. 6: Experimental and predicted values of swelling content for films of HPMC matrices

Experimental and predicted values of swelling content based on linear Peleg model for films of A) HPMC E5 matrix and B) HPMC K15M matrix (•) DM5C0, (ם) DM5C1, ( 4 ) DM5C2, (O) DM5C3, (×) DM5C4

hydration level of cornea is $76-80 \%$ and the level above $83 \%$ is an indication of damage to the epithelium and/ or endothelium of the corneal tissue ${ }^{[9,22]}$. The result of the corneal hydration level on the corneas treated with film formulation was found to be not exceeding $83 \%$ (fig. 8). This indicated that the presence of kaolin in the drug delivery film can maintain a safe corneal hydration level after topical application.

Swelling behaviour of DXA incorporated HPMC ocular film in presence and absence of kaolin was investigated. FTIR spectra of films showed evidence for uniform distribution of kaolin in the HPMC matrix and interaction between kaolin and DXA. SEM micrographs confirmed the plate shaped DXA converted to wire-like shape in presence of kaolin in the film. The gradual reduction of swelling content and swelling rate were observed with corresponding
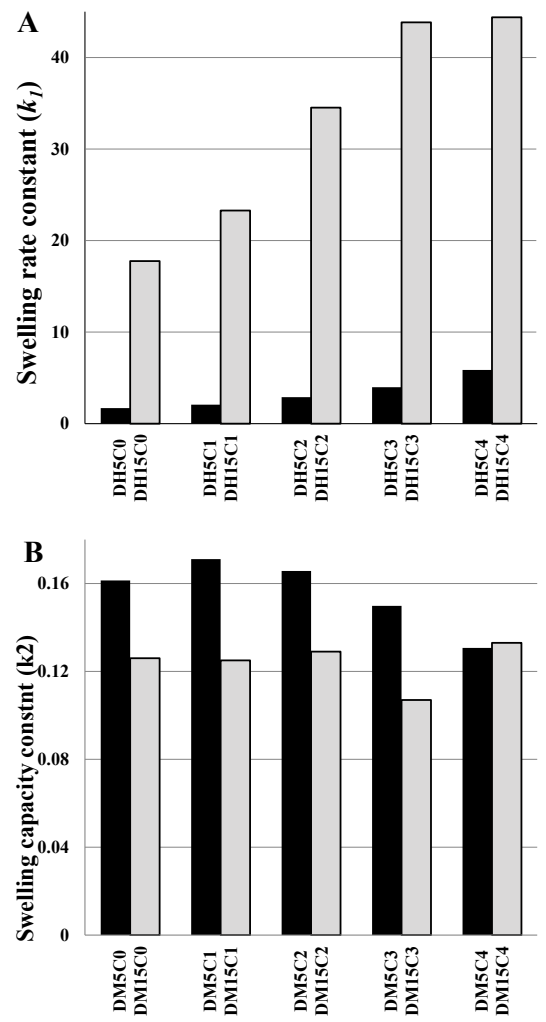

Fig. 7: Swelling rate and capacity constants as a function of kaolin in HPMC film formulations

A) Dynamic swelling Peleg rate constant $\left(k_{l}\right)$ and (B) swelling capacity constant $\left(k_{2}\right)$ as a function of kaolin in HPMC film formulations

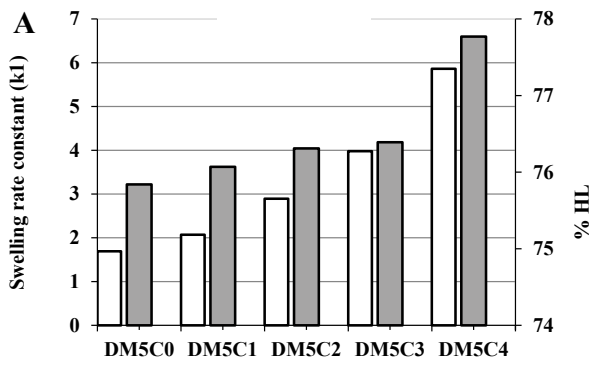

B

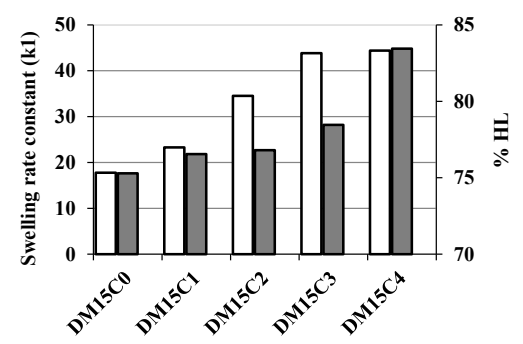

Fig. 8: Relationship between the swelling rate and hydration level of the films

Relationship between swelling rate and hydration level of the films A) DM5C0, DM5C1, DM5C2, DM5C3, DM5C4 and B) DM15C0, DM15C1, DM15C2, DM15C3, DM15C4. (ð) K1 (घ) HL 
increased loading of kaolin in both HPMC matrices. The Peleg's rate constant $\left(k_{1}\right)$ increased with increasing kaolin content in films whereas the capacity constant $\left(k_{2}\right)$ decreased. Patterned swelling of the ocular film in presence of kaolin could maintain a safe hydration level without damaging endothelium of the corneal tissue.

\section{Conflicts of interest:}

The authors declare that there is no conflict of interest.

\section{Acknowledgements:}

The authors are grateful to the president, Siksha'O'Anusandhan (Deemed to be University) Prof. (Dr.) Monojranjan Nayak for financial support and laboratory facilities. Authors grateful to the Pharmacia Upjohn Company and Birla Institute of Technology, Mesra, Ranchi, for gift sample and instrumentation facility, respectively.

\section{REFERENCES}

1. Panda B, Subhadarsini R, Mallick S. Biointerfacial phenomena of amlodipine buccomucosal tablets of HPMC matrix system containing polyacrylate polymer/ $\beta$-cyclodextrin: correlation of swelling and drug delivery performance. Expert Opin Drug Del 2016;13(5):633-43.

2. Birsan M, Cojocaru IC, Stamate MI, Teodor V, Tuchilus C. Antifugal action of imidazole derivatives from new pharmaceutical forms on various strains of candida. Rev Chim 2016;67:1385-8.

3. Mohapatra R, Mallick S. Transient and steady state characterization of permeation kinetics of diclofenac through ocular tissue. Asian J Chem 2016;28:1149-54.

4. Mohapatra R, Mallick S, Nanda A, Sahoo RN, Pramanik A, Bose A et al. Analysis of steady state and non-steady state corneal permeation of diclofenac. RSC Adv 2016;6(38):3197687.

5. Sang J, Li X, Shao Y, Li Z, Fu J. Controlled tubular unit formation from collagen film for modular tissue engineering. ACS Biomater Sci Eng 2016;3(11):2860-8.

6. Mateescu A, Wang Y, Dostalek J, Jonas U. Thin hydrogel films for optical biosensor applications. Membranes 2012;2(1):40-8.

7. Swain K, Pattnaik S, Sahu SC, Mallick S. Feasibility assessment of ondansetron hydrochloride transdermal systems: physicochemical characterization and in vitro permeation studies. Lat Am J Pharm 2009;28:706-14.

8. Panda B, Parihar AS, Mallick S. Effect of plasticizer on drug crystallinity of hydroxypropyl methylcellulose matrix film. J Biol Macromol 2014;67:295-302.

9. Pinto FCH, Silva-Cunha A, Pianetti GA, Ayres E, Orefice RL, Da Silva GR. Montmorillonite clay-based polyurethane nanocomposite as local triamcinolone acetonide delivery system. J Nanomater 2011;2011:1-11.

10. Mali KK, Dhawale SC, Dias RJ, Dhane NS, Ghorpade VS. Citric acid crosslinked carboxymethyl cellulose-based composite hydrogel films for drug delivery. Indian J Pharm Sci 2018;80(4):657-67.

11. Kawarkhe S, Poddar SS. Designing of the mucoadhesive intravaginal spermicidal films. Indian $\mathrm{J}$ Pharm Sci 2010;72(5):652-5.

12. Peppas NA, Bures P, Leobandung W, Ichikawa H. Hydrogels in pharmaceutical formulations. Eur $\mathrm{J}$ Pharm Biopharm 2000;50(1):27-46.

13. Peleg M. An empirical model for the description of moisture sorption curves. J Food Sci 1988;53(4):1216-7.

14. http://www.originlab.com/OriginProLearning.aspx

15. Mallick S, Pattnaik S, Swain K, De PK, Saha A, Ghosal G, et al, Formation of physically stable amorphous phase of ibuprofen by solid state milling with kaolin. Eur J Pharm Biopharm 2008;68(2):346-51.

16. Tita B, Morgovan C, Tita D, Neag TA. Anti-inflammatory drugs interacting with $\mathrm{Zn}$ (ii) metal ion synthesis, characterization and thermal behaviour of the complex with ketoprofen. Rev Chim 2016;67:38-41.

17. Tita B, Furau G, Marian E, Tita D, Furau C. Antiinflammatory drugs interacting with $\mathrm{Cu}$ (ii) metal ion synthesis, characterization and thermal behaviour of the complex with ketoprofen. Rev Chim 2016;67:706-10.

18. Doile MM, Fortunato AK, Schmücker IC, Schucko SK, Silva MA, Rodrigues PO. Physicochemical properties and dissolution studies of dexamethasone acetate- $\beta$-cyclodextrin inclusion complexes produced by different methods. AAPS Pharm Sci Tech 2008;9(1):314-21.

19. Saikia BJ, Parthasarathy G. Fourier transform infrared spectroscopic characterization of kaolinite from Assam and meghalaya, northeastern India. J Mod Phys 2010;1(4):206-10.

20. Kristo J, Frost RL, Felinger A, Mink J. FTIR spectroscopic study of intercalated kaolinite. J Mol Struct 1997;410-1:11922.

21. Pruett RJ, Murray HH. The mineralogical and geochemical controls that source rocks impose on sedimentary kaolins. In: Murray HH, Bundy WM, Harvey CC, editors, Kaolin genesis and utilization. vol 16 The Clay Minerals Society. Boulder: Colorado; 1993. p. 149-70.

22. Wiewiora A, Brindley GW. Potassium acetate intercalation in kaolinite and its removal: effect of material characteristics. Proc Int Clay Con Tokyo 1969;1:723-9.

23. Ghebaur A, Garea SA, Cecoltan S, Iovu H. Development and characterization of novel freeze-thawed polyvinyl alcohol/ halloysite hydrogels an approach for drug delivery application. Mater Plast 2017;1:8-13.

24. Saada A, Siffert B, Papirer E. Comparison of the hydrophilicity/ hydrophobicity of illities and kaolinites. J Colloid Interface Sci 1995;174(1):185-90.

25. Turhan M, Sayar S, Gunasekaran S. Application of peleg model to study water absorption in chickpea 